DOI: https://doi.org/10.29105/gmjmx18.34-7

Artículos

\title{
COBERTURA Y TRATAMIENTO DE LA CARAVANA MIGRANTE 2018 EN LA PRENSA DIGITAL DE NUEVO LEÓN Y CHIAPAS
}

\section{COVERAGE OF THE 2018 MIGRANT CARAVAN IN THE DIGITAL PRESS OF NUEVO LEÓN AND CHIAPAS}

\section{Gioconda Portales Esquivel}

Tecnológico de Monterrey, México

(D) https://orcid.org/0000-0003-4491-4712

\section{Oscar Mario Miranda Villanueva}

Tecnológico de Monterrey, México

(iD) https://orcid.org/0000-0003-3180-889X

Autor para correspondencia: Gioconda Portales Esquivel, email: portalesesquivel@ gmail.com

\section{Resumen}

Se analizó la cobertura y tratamiento noticioso de la Caravana Migrante 2018 en la prensa digital de los estados mexicanos de Nuevo León y Chiapas. Dos aproximaciones teóricas son discutidas: el establecimiento de la agenda y el encuadre. Se utilizó un enfoque cuantitativo mediante el análisis de contenido para estudiar 120 historias periodísticas seleccionadas de forma aleatoria en los siguientes periódicos: El Norte, El Horizonte y ABC Noticias de Nuevo León; El Orbe, Diario del Sur y El Heraldo de Chiapas de Chiapas. Se encontró que el encuadre de entrada irregular de migrantes fue el más usado en los diarios de los dos estados, mismos que tuvieron una tendencia a usar en mayor medida a los actores políticos para otorgarle validez a sus historias periodísticas.

Palabras clave: análisis de contenido, Caravana Migrante 2018, cobertura y tratamiento periodístico, prensa digital mexicana.

\begin{abstract}
This study analyzed the journalistic coverage of the 2018 Migrant Caravan in the digital press of two Mexican states, Nuevo León and Chiapas. Two theoretical approaches are discussed: agenda-setting and framing. A quantitative approach through content analysis was used to study 120 randomly selected news stories in the following newspapers: El Norte, El Horizonte, and ABC Noticias of Nuevo León; El Orbe, Diario del Sur, and El Heraldo de Chiapas of Chiapas. It was found that the framing of irregular entry of migrants was the most used in the newspapers of the two states, which tended to use political actors largely to validate their journalistic stories.
\end{abstract}

Keywords: content analysis, 2018 Migrant Caravan, journalistic coverage \& treatment, Mexican digital press.

Global Media Journal México, 18(34), 137-159, enero - junio 2021. 
Recibido: 20/03/2021

Aceptado: 09/05/2021

\section{Introducción}

Aunados a la violencia que ha sacudido a los países centroamericanos desde la década de los 90, los factores económicos, políticos y de inseguridad han influido de sobremanera en la decisión de sus habitantes de migrar (Castillo y Toussaint, 2015) a los países del norte. Debido a las medidas restrictivas que han sido impuestas por el gobierno de Estados Unidos, cruzar la frontera es cada día más difícil, sobre todo para los individuos que no cuentan con su papelería en orden. En el mes de octubre de 2018 una cantidad considerable de centroamericanos se unieron para avanzar hacia el norte en un suceso denominado por los medios de comunicación como la caravana migrante.

Estados Unidos ha enfrentado un problema con la inmigración de mexicanos desde hace varias décadas. De 1942 a 1964 se puso en marcha el programa bracero que consistió en un acuerdo entre los dos países para la contratación de mexicanos en Estados Unidos (Canales Lizaola y Lizárraga Salas, 2019). Tras la culminación del programa, la inmigración de mexicanos y latinoamericanos continuó de manera ilegal. Antes de la década de los 80, los gobiernos de Estados Unidos y México prestaron escaso interés a la migración de centroamericanos hacia los países del norte (Castillas, 2008). En los 90 México instauró una nueva política inmigratoria y transmigratoria que pretendió controlar los flujos de dicha migración. Las políticas más fuertes para controlar la entrada de personas migrantes mexicanos a Estados Unidos comenzaron después del 11 de septiembre de 2001.

Con la llegada de Donald Trump en 2017 a la presidencia de Estados Unidos las leyes de migración fueron reforzadas, y aunque durante el último año de la presidencia de Enrique Peña Nieto ${ }^{1}$ en México se puso en marcha el plan llamado "Estas en tu casa", destinado al bienestar de los migrantes en materia de salud, educación y empleo (El Colegio de La Frontera Norte, 2018), la situación para las personas migrantes siguió siendo compleja. Recientemente, a pesar de la visita del Presidente de México, Andrés Manuel López Obrador, a Estados Unidos $^{2}$, y de la omisión en discutir el tema migratorio, el discurso adverso del presidente Trump hacia las personas migrantes latinoamericanos ha colocado dicho tema en la agenda de los medios de comunicación de ambos países. Debido a las nuevas leyes y políticas migratorias, los centroamericanos y sudamericanos tuvieron que buscar nuevas formas para cruzar las fronteras de México y Estados Unidos sin documentos. La migración indocumentada es un

\footnotetext{
${ }^{1}$ Mandato presidencial 2012-2018.

${ }^{2}$ El 8 de julio de 2020.
}

Global Media Journal México, 18(34), 137-159, enero - junio 2021. 
reto constante a la creatividad, muy particular de quienes hacen de ella su recurso diario para subsistir.

Igartua et al. (2008) observan que los encuadres noticiosos sobre la inmigración no sólo encauzan respuestas sino que también contribuyen de manera indirecta a la formación de juicios sobre determinado tema. De acuerdo a Igartua et al. (2006), la acción informativa de los medios de comunicación se transforma en un factor situacional que ayuda a generar imágenes de discriminación y exclusión social colectiva, ya que fortalece una imagen problemática de la inmigración. Además, el discurso de los medios de comunicación en la mayoría de los países europeos está centrado primordialmente en llegadas y entradas ilegales, crímenes, desviaciones y en la recepción e integración de problemas propios de los inmigrantes (Van Dijk, 2006).

La pregunta general de este estudio, por lo tanto, es en qué medida se dan los encuadres noticiosos sobre la migración en la cobertura y tratamiento noticioso de la Caravana Migrante 2018 en la prensa digital de los estados de Nuevo León, en la frontera con Estados Unidos, y Chiapas, en la frontera con Guatemala. Aunque Ramos-Rojas y Martínez-Mendoza (2021) estudian las narrativas sobre migración en diez portales informativos de México afiliados a la Alianza de Medios Tejiendo Redes, los periódicos seleccionados para este estudio son: El Norte, El Horizonte y ABC Noticias de Nuevo León; y El Orbe, Diario del Sur y El Heraldo de Chiapas de Chiapas. La razón por la cual se seleccionaron dichos periódicos es porque su edición se encuentra en puntos de entrada, salida y tránsito de personas migrantes centroamericanos hacía
Estados Unidos, lo cual los hace atractivos para estudiar los encuadres noticiosos sobre la migración en función de los periódicos de tirada nacional (Muñiz, 2011). Además, los usuarios mexicanos tienden a hacer mayor uso de sitios en línea como fuente de información, mientras que los recursos impresos se ubican por debajo (Gutiérrez Rentería, 2018).

A continuación, se definen los conceptos que se utilizan en esta investigación: migración, migrante, y el sintagma caravana migrante. La migración es una transición social y espacial; debe ser un traslado considerable y a cierta distancia significativa. Además, las personas que migran deben contar con alguna disposición de permanecer en el lugar (Arango, 1985). La migración es un acontecimiento colectivo de movimientos geográficos del ser humano y un producto de la globalización (Solis Contreras, 2018). Las personas que migran buscan desplazarse a lugares donde las ganancias recibidas por su trabajo sean mayores que las que obtienen en su país (Arango, 2003). De acuerdo con la Organización Internacional para las Migraciones (IOM, por sus siglas en inglés) (2019), un migrante es cualquier persona que se desplaza o se ha desplazado a través de una frontera internacional o dentro de su mismo país, fuera de su lugar de residencia.

La palabra caravana hace referencia a los individuos centroamericanos que viajan en grupo y que se desplazan a través de las fronteras de algunos países de Centroamérica y de México hacia Estados Unidos. "Las caravanas [refiriéndose a las caravanas de personas migrantes centroamericanos] son una 
rebelión, una insurgencia de las víctimas del neoliberalismo en América Central, al mismo tiempo que una insurrección al gobierno fronterizo establecido por los estados de la región" (Varela y McLean, 2019, p. 167). Estos actores han sido denominados por la prensa internacional y nacional como caravana de migrantes. Dentro de la prensa mexicana ha sido usado el término caravana migrante, el cual alude a "personas centroamericanas que cruzan el país para llegar a la frontera norte" (Caballo, 2018, p.1).

En la presente investigación se aborda la caravana de migrantes que entra a México en octubre de $2018^{3}$. El lapso de las notas analizadas comprende desde el 8 de octubre hasta el 5 de diciembre de 2018, periodo en el que México se encuentra bajo la presidencia de Enrique Peña Nieto, mientras que Andrés Manuel López Obrador ya se halla posicionado como el mandatario electo para el sexenio 2019-2024.

\section{Marco teórico}

A continuación, se describen dos aproximaciones teóricas desde las cuales se discute el presente fenómeno de estudio: el establecimiento de la agenda (Canales Lizaola y Lizárraga Salas, 2019; Carniel Bugs et al., 2018; Coleman et al., 2009; De Cock et al., 2019; Guerra Salas y Gómez Sánchez, 2017;
Lams, 2019; McCombs, 2006, 2014; McCombs y Ghanem, 2001; McCombs y Valenzuela, 2007; Muñiz et al., 2007a; Tortajada, 2007), y la teoría del encuadre (Ardèvol-Abreu, 2015; De Vreese, 2005; Entman, 1993; Goffman, 1974; Hertog y McLeod, 2001; Igartua et al., 2004; Igartua et al., 2005; Igartua y Muñiz, 2004; Muñiz, 2011; Muñiz et al., 2007b; Muñiz et al., 2008; Ramos, 2015; Valkenburg et al., 1999; Zuloaga Lojo, 2016).

Mientras que la agenda de los medios de comunicación mexicanos se encarga de elegir los sucesos que serán de relevancia para la población, con la ayuda de los encuadres, el público es capaz de comprender un evento de cierta forma. Como menciona De Vreese (2005), la manera en que los medios de comunicación masiva pueden moldear a la opinión pública es mediante el encuadre de los eventos.

\section{El establecimiento de la agenda}

Agenda-setting se refiere al proceso llevado a cabo por los medios para mostrar ciertos problemas frecuentemente con el propósito de que el público perciba a estos eventos como más importantes que otros (Coleman, et al., 2009). El papel de la agenda setting en los medios de comunicación es el de colocar prominencia a un problema (McCombs, 2014), e influir en las percepciones de sus lectores acerca de cuáles son los temas más importantes del día (McCombs, 2006; McCombs y Valenzuela,

\footnotetext{
${ }^{3}$ Esta caravana es la denominada por los medios como la primera que entró a territorio nacional, mientras que la segunda caravana surge en enero de 2019.
} 
2007). McCombs y Ghanem (2001) expresan que es una teoría que se refiere a la transferencia del objeto saliente, y es la agenda de los medios la que establece la agenda pública.

Por ejemplo, Tortajada (2007) destaca la nula presencia de la voz de asociaciones de inmigrantes y de representantes de los grupos culturales en cinco cadenas que tienen cobertura en territorio catalán: TVE1, La 2, Antena 3 TV, Tele 5 y TV3. La información de los noticieros cuenta con un enfoque eurocéntrico, segrega la voz de las personas inmigrantes y magnifica la situación. Las noticias analizadas se centran en detallar las medidas adoptadas por los gobiernos y las acciones gubernamentales. Las cadenas de TV priorizan todo lo relacionado con el conflicto político; con el conflicto social, como las denuncias de las organizaciones no gubernamentales; y con la emoción, como el sufrimiento de las personas migrantes.

De Cock et al. (2019) encuentran diferencias y similitudes entre periódicos belgas y suecos respecto a la crisis de refugiados en el periodo de 2015 a 2017. En Bélgica, los temas más tratados son la respuesta política a la situación de los refugiados, los suministros de ayuda para los refugiados y su integración. En Suecia, se encuentra el tema de la respuesta política a la situación, la respuesta de la sociedad civil y el viaje de los refugiados. Los dos periódicos suecos le conceden mayor atención al tema de los refugiados. En la mayoría de los periódicos estudiados los refugiados son representados colectivamente.
Lams (2019) explica el rol del refugiado dentro del periódico holandés De Volkskrant y el periódico belga De Morgen. En este último periódico, el refugiado obtiene una posición pasiva, mientras que en De Volkskrant obtiene la posición del receptor de la acción. En ambos, el refugiado es mostrado como el beneficiario de la ayuda otorgada. La Unión Europea como institución ocupa el rol del agente dominante. El gobierno de Angela Merkel obtiene un rol de agente en la mayoría de los artículos publicados en ambos diarios. El primer ministro hungaro, Victor Orban, adquiere el rol de agente en ambos periódicos. El refugiado es silenciado; no se le concede espacio para contar su propia historia.

Canales Lizaola y Lizárraga Salas (2019) identifican durante los cien primeros días del gobierno del presidente Trump, 21 notas en $L a$ Jornada y El Universal de México y el tabloide estadounidense La Opinión, las cuales colocan en la portada y primera plana el tema de la migración. La mayoría de las notas son de La Opinión. La mayor parte de ellos aborda la temática social, enfocándose en manifestaciones y protestas, seguido por la temática política. Los actores políticos más mencionados en La Opinión son el gobierno de Estados Unidos, el Servicio de Inmigración y Aduanas de Estados Unidos (ICE) y Donald Trump; en El Universal, Trump, Carlos Salinas de Gortari y Madeleine Albright; y en La Jornada, Miguel Ángel Mancera, Rahm Emanuel y la Conferencia Nacional de Gobernadores (CONAGO). Los verbos positivos usados en la construcción de las noticias ayudan a crear una imagen beneficiosa de las personas migrantes, y los verbos negativos contribuyen a la 
creación de imágenes negativas respecto al gobierno de Estados Unidos. Los actores a los que se les concede mayor importancia son los gobernantes, invisibilizando la voz del migrante.

Guerra Salas y Gómez Sánchez (2017) encuentran que los temas más mencionados en diarios latinoamericanos de habla hispana son las migraciones y los asuntos de política internacional. El Mercurio de Chile, La Nación de Argentina, El Comercio de Perú, El Tiempo de Colombia, Reforma de México y El Nuevo Día de Puerto Rico mencionan más a Estado Unidos en las notas. El tema más señalado en los titulares y el primer párrafo de los periódicos El País, ABC y 20 Minutos de España es migración y política nacional. España es la región más mencionada en los diarios españoles, seguida de la Unión Europea. Los autores identifican que en el subcorpus latinoamericano los sintagmas más sobresalientes son crisis migratoria y debate migratorio, mientras que en el subcorpus español, son población española e integración europea. El sintagma más fuerte que tienen en común ambos subcorpus es el de política migratoria.

Carniel Bugs et al. (2018) muestran que la prensa $^{4}$ al norte del mediterráneo realiza una mayor cobertura de la información relacionada con la migración. El tema más relevante es la relación entre migración y delincuencia, y la integración de las personas migrantes en el país de acogida. En los tabloides se utiliza el origen de las personas para nombrar a los individuos. Los titulares hacen

4 Periódicos seleccionados: El Khabar y El Watar de Argelia, ABC y El País de España, Al Ahram y Al Dostur de Egipto, Le Monde y Le Figaro de Francia, Attounissia referencia primeramente a los individuos, seguido por actores institucionales y sociales. Los actores institucionales destacados en la prensa son el gobierno y las fuerzas del orden.

\section{La teoría del encuadre}

La interpretación que hacen las personas de la realidad y de la vida diaria depende enteramente de la interacción y definición de las situaciones (Ardèvol-Abreu, 2015). El sociólogo Ervin Goffman (1974) define el frame como una situación que se edifica siguiendo los principios de organización que gobiernan eventos sociales y nuestra participación subjetiva en los mismos.

Los comunicadores en general cuentan una historia en un espacio y tiempo limitado para hacer los eventos accesibles a largas audiencias (Valkenburg et al., 1999). Los periodistas emplean el encuadre para dar sentido a los eventos, simplificar la realidad y mantener el interés de la audiencia. Cuando el periodista construye la noticia, arma con palabras e imágenes la descripción de un aspecto de la realidad, se selecciona un encuadre; es casi imposible abordar un asunto desde todas sus perspectivas (Ardèvol-Abreu, 2015). El periodista tiene la posibilidad de encuadrar la misma información de maneras diferentes. Los encuadres forman parte de la estructura de la cultura y proveen una parte del significado común entre los individuos de la sociedad; son necesarios para mantener el orden

y Al-Chourouk de Túnez, Il Corriere della Sera y La Repubblica de Italia, The Guardian y The Times de Reino Unido, Al Massae y AsSabah de Marruecos. 
social y facilitar la interacción entre miembros de la comunidad (Hertog y McLeod, 2001). "Los encuadres tienen cuatro ubicaciones en el proceso comunicativo: el comunicador, el texto, el receptor y la cultura" (Entman, 1993, p. 52).

El estudio de Igartua y Muñiz (2004), por ejemplo, trata la nacionalidad de las personas inmigrantes referidos en las notas de cuatro tabloides españoles: El País, El Mundo, ABC y La Razón. La mayoría de ellos muestra migrantes africanos, seguido por los latinoamericanos. El control de fronteras es uno de los temas que más se maneja en los medios seleccionados, seguido por los avances en la convivencia y la lucha contra las mafias y el tráfico ilegal de individuos inmigrantes. La mayoría de las noticias poseen características negativas hacia los inmigrantes. Los resultados del estudio muestran la relación de los inmigrantes de África o de Europa del Este con noticias referidas al control de fronteras y lucha contra las mafias. A las personas migrantes de origen latinoamericano se les asocia con notas relacionadas a los avances en la convivencia y políticas activas de empleo. Los encuadres que predominan en las noticias son el de atribución de responsabilidad, el de interés humano y el de conflicto.

Muñiz (2011) detecta los encuadres genéricos referentes al tema de la migración que se encuentran con mayor presencia en tres periódicos mexicanos: Milenio, Reforma y El Universal, e identifica el encuadre de atribución de responsabilidad, seguido por el de conflicto y el de interés humano. El encuadre de debate político posee una tendencia a presentarse junto con el encuadre de conflicto y atribución de la responsabilidad. El encuadre de procesos regulatorios se halla relacionado con el encuadre de conflicto. El encuadre de delincuencia y expulsión se asocia con el de consecuencias económicas. Se identifica que en las noticias que tuvieron lugar en México dominan el encuadre de delincuencia y expulsión de migrantes, y en las notas que narran hechos ocurridos en Estados Unidos, Europa y el norte de África predomina el encuadre de debate político. Los encuadres que cuentan con mayor presencia en las notas son el de debate político en torno a la regulación migratoria, y delincuencia y expulsión de personas migrantes.

Igartua et al. (2005) encuentran que los cinco encuadres más utilizados en las noticias analizadas en su estudio son el referente a la información sobre políticos y/o representantes del gobierno y sobre la Ley de Extranjería, seguido por la entrada irregular de inmigrantes en pateras, las actuaciones sobre menores inmigrantes, los inmigrantes se posicionan como delincuentes, y las acciones de gestión de fronteras a nivel comunitario para potenciar la inmigración legal y frenar la llegada masiva de inmigrantes.

Zuloaga Lojo (2016) realiza un análisis en dos diarios españoles: El País y El Mundo. En las notas de estos tabloides prevalece un trato negativo y conflictivo de la inmigración. La mayoría de sus titulares se enfocan en la Ley de Extranjería y las pateras. En el diario El País se halla una gran cantidad de titulares acerca de los individuos y las embarcaciones detectadas. Las palabras avalancha y oleada son usadas constantemente. Los diarios publican acerca del riesgo de las enfermedades que 
pueden ser portadas por migrantes africanos como la tuberculosis o el SIDA. Los titulares de El País y El Mundo presentan a los individuos inmigrantes como protagonistas de sucesos delictivos. La manera en que se presenta al inmigrante se ordena en tres niveles: el inmigrante como víctima de agresiones, la nacionalidad del sujeto migrante y el migrante como delincuente.

Muñiz et al. (2008) hallan que la mayoría de las notas periodísticas referentes a la inmigración en cuatro diarios: El País, El Mundo, ABC y La Razón, son colocadas en la sección de nacional y predominan ligeramente más las de carácter positivo.

Los encuadres que imperan en la información son los inmigrantes como delincuentes, la entrada irregular de inmigrantes, la contribución económica de los trabajadores inmigrantes, la descripción de la experiencia migratoria como proyecto vital y la presentación de los inmigrantes como víctimas de agresiones. El encuadre positivo más destacado es el de contribución económica, mientras que el negativo es el de inmigrantes como delincuentes. Se observa un repunte de la negatividad en las notas referentes a la inmigración.

Los resultados obtenidos por Igartua et al. (2004) muestran como cuatro diarios españoles tienden a enfocar de manera distinta el tema de la inmigración y los inmigrantes debido a sus diferentes ideologías y modelos de diario. El País destaca el encuadre referente a información sobre políticos y/o representantes del gobierno y sobre la Ley de Extranjería. $E l \quad A B C$ utiliza el encuadre antes mencionado, pero el diario le da un enfoque más conservador vinculando la delincuencia con la inmigración. El Mundo, un periódico más liberal pero sensacionalista, tiende a enfatizar los encuadres relacionados con la problemática social sufrida por los inmigrantes. La Razón se inclina a presentar a las personas inmigrantes como víctimas de abusos y agresiones, de una manera sensacionalista. Los encuadres dominantes en los cuatro diarios son las actuaciones del gobierno en torno a la Ley de Extranjería, la entrada irregular de inmigrantes en pateras, los actos sobre menores inmigrantes, los inmigrantes como delincuentes y las acciones de gestión de fronteras para favorecer la inmigración legal.

Ramos Rojas (2015) halla que en la investigación de dos tabloides mexicanos, El Informador y Mural, el encuadre de la ruta migratoria aparece mayormente en el año 2009 en $E l$ Informador. La mayoría de las fuentes de información son voceros oficiales. Los individuos migrantes están detrás; los periodistas no les conceden la palabra. La mayoría de los inmigrantes son presentados como indocumentados, centroamericanos y víctimas; refiriéndose mayormente a su nacionalidad. Las mujeres únicamente se presentan en notas cuando sufren una violación sexual. El encuadre de los derechos humanos no es muy empleado, apareciendo sólo siete veces en 2010. El tema del crimen organizado posee una mayor presencia en los tabloides que la migración.

En la prensa mexicana el migrante es representado en dígitos, se cosifica. También hay que destacar que, desde el suceso que ocurre en San Fernando, Tamaulipas, en el año 2010, en donde 72 
personas migrantes son secuestradas, asesinadas y enterradas, los encuadres usados por la prensa comienzan a adquirir un enfoque muy distinto al anterior. Los migrantes empiezan a ser representados como víctimas en lugar de como criminales, y la prensa le presta más atención al tema. En función de la revisión de la literatura, a continuación, se presentan las preguntas específicas de investigación:

- ¿De qué manera se habla de los actores protagonistas e implicados en la prensa digital de Nuevo León y Chiapas?

- ¿Desde cuál perspectiva es abordado el hecho en dicha prensa?

- ¿Cuáles son las diferencias encontradas entre los encuadres predominantes en la prensa digital de Nuevo León y Chiapas?

\section{Datos y metodología}

Los diarios de Nuevo León que se estudiaron son El Norte, El Horizonte y ABC Noticias. Los diarios de Chiapas que se consideraron son $E l$ Orbe, Diario del Sur y El Heraldo de Chiapas. El universo de la población comprendió todas las notas periodísticas sobre la caravana migrante acontecida en octubre de 2018 en la prensa digital de Nuevo León y Chiapas que contaran con los siguientes sintagmas en el título de la nota: caravana migrante, caravana de migrantes, migrantes centroamericanos, fenómeno migratorio y flujo migratorio. Además de las palabras: migrantes, inmigrantes, transmigrantes y caravana. El periodo de análisis de las notas fue del ocho de octubre al cinco de diciembre de 2018, fechas en las cuales aparecieron la primera y la última historia periodística contemplada.

Se recolectaron 785 historias periodísticas de los tres diarios de Nuevo León $(n=247)$ y los tres diarios de Chiapas $(n=538)$. Del diario El Norte se obtuvieron 47 historias, de El Horizonte 93, y del ABC Noticias 107. Mientras que de los diarios de Chiapas se obtuvieron 143 de El Orbe, 240 del Diario del Sur y 155 de El Heraldo de Chiapas. Debido a que se identificó que las notas con estas palabras y sintagmas eran las más propensas a contener información acerca de las personas inmigrantes centroamericanos, el objeto de análisis fue el texto periodístico completo; se contempló como historia periodística la noticia, el reportaje y el artículo de opinión.

La técnica de investigación que se utilizó fue el análisis de contenido, debido a que es una técnica que permite descubrir el núcleo de los mensajes mediáticos, su estructura, sus componentes básicos y su funcionamiento (Igartua y Humanes, 2004). El análisis de contenido (Krippendorff, 2004; Wimmer y Dominick, 2001) consta de tres elementos: el sistemático, el objetivo y el cuantitativo. El sistemático se refiere a que la selección de la muestra tiene que seguir un procedimiento 
normalizado y riguroso; en este estudio cada uno de los elementos del universo tuvo idénticas posibilidades de ser incluido en el análisis. El objetivo habla de que la idiosincrasia peculiar o los sesgos propios del investigador no pueden afectar a los resultados, y el cuantitativo se refiere a que su aplicación permite transformar un documento en una serie de resultados cuantitativos y numéricos.

Se realizó un muestreo aleatorio sistemático (Hernández et al. 2014) para extraer de las 785 historias periodísticas del universo 120 para su análisis. Primero, se obtuvo del total el porcentaje correspondiente a la cantidad de notas de cada periódico. Ya sabiendo dicho porcentaje, se obtuvo a través de un salto sistemático el número de notas para la muestra de 120 a analizar. De El Norte se obtuvieron 6\% $(n=7)$ del total de las 785 historias periodísticas, de El Horizonte 12\% $(n=15)$, del ABC Noticas 14\% $(n=17)$, de El Orbe 18\% $(n=21)$, del Diario del Sur $30 \%(n=36)$ y de El Heraldo de Chiapas $20 \%(n=24)$. Finalmente, se comprobó que la suma de las notas seleccionadas de cada periódico resultara en 120.

El salto sistemático se llevó a cabo colocando en carpetas el total de notas de cada periódico, organizandolas alfabéticamente empezando con la letra A. Después se dio comienzo al salto sistemático, seleccionando la primera nota de la carpeta para la muestra y prosiguiendo hacia abajo contando seis notas; la sexta se escogía para la muestra. Las notas seleccionadas se copiaron a una carpeta que tenía por nombre muestra, realizando una carpeta para cada diario.

En la elaboración del manual de codificación se consideraron dos dimensiones: establecimiento de la agenda y teoría del encuadre. En relación con la primera dimensión (Canales Lizaola y Lizárraga Salas, 2019; Tortajada, 2007) se midieron las siguientes categorías: la perspectiva desde la cuál es abordado el hecho, los actores implicados en el suceso y de qué manera se habla de cada uno, y el actor protagonista de la nota.

En cuanto a la segunda dimensión, para la construcción de los encuadres se empleó la escala de Encuadres Noticiosos de la Inmigración (ENI) elaborada por Igartua et al. (2005) y Muñiz (2011), que consta de 14 encuadres (ver Tabla 4). De los encuadres mencionados por estos autores se seleccionaron los siguientes para este estudio: la entrada irregular de inmigrantes; el debate político en torno a la política sobre inmigración; las medidas de gestión de fronteras; la tramitación de documentos y regularización de inmigrantes; la contribución económica de los inmigrantes definidos como trabajadores; los inmigrantes como delincuentes y vinculados con mafias $\mathrm{u}$ organizaciones delictivas; los inmigrantes como 
víctimas de agresiones, malos tratos o actos xenófobos; la expulsión y devolución de inmigrantes a sus países de origen; y la descripción de la experiencia migratoria como proyecto vital.

El encuadre de actuaciones sobre menores inmigrantes no fue considerado en esta investigación debido a que los integrantes de la caravana migrante de octubre 2018 son, en su mayoría, jóvenes y adultos. Además, la presencia de niños y niñas no se destaca en las notas de los diarios. Aunado a la selección de la escala ENI, se consideraron los encuadres de acontecimiento narrado (Muñiz, 2011), de atribución de la responsabilidad, el de interés humano, el encuadre de conflicto, el de moralidad (Semetko y Valkenburg, 2000) y el de consecuencias económicas.

Una vez terminado el manual de codificación, se realizó un pilotaje para asegurar que funcionara de manera correcta; para ello se codificaron 30 notas periodísticas en donde se incluyeron notas de los seis diarios. Se detectaron algunos errores y se realizaron los ajustes considerados necesarios.

Para la codificación de las 120 historias periodísticas que conformaron la muestra se contó con un equipo de trabajo de cinco personas, quienes fueron entrenadas para la codificación según lo recomendado por los autores que discuten el análisis de contenido (Krippendorff, 2004; Wimmer y Dominick, 2001). Los análisis de la base de datos se hicieron a través del programa $\operatorname{SPSS}^{5}$ y Microsoft Excel.

\section{Resultados}

Se elaboraron las siguientes tablas para dar respuesta a la cobertura y tratamiento de la caravana migrante de 2018 en la prensa digital de los estados de Nuevo León y Chiapas, en particular, a la manera en que se presentaron los actores protagonistas e implicados en las historias periodísticas, la perspectiva desde la cual se abordaron dichas historias y los encuadres que se emplearon para ello. A pesar de que se analizaron 120 historias periodísticas en total, la cuantificación y sus porcentajes se hizo en función del número total de actores, perspectivas y encuadres dentro de dichas historias. Esto debido a que en éstas se puede hablar de varios actores o abordar el tema desde distintas perspectivas o encuadres. Por ende, se acordó analizar la información de tal forma.

\section{Actores protagonistas de la historia periodística}

La Tabla 1 muestra los actores que tienen un rol protagonista en la construcción de la historia, ya sea

\footnotetext{
${ }^{5}$ Statistical Package for the Social Sciences por sus siglas en inglés.
} 
porque su opinión fue tomada en cuenta por los periodistas a través de una entrevista o porque se alude a información de ellos en la historia. Los individuos inmigrantes son los actores con mayor protagonismo, ocupan un $43.9 \%(n=82)$, seguidos por el gobierno 6 , 25.1\% $(n=47)$, y las fuerzas del $\operatorname{orden}^{7}, 13.3 \%(n=25)$. Los inmigrantes son más frecuentemente protagonistas en los periódicos de Chiapas, 63.4\% $(n=52)$, que en los periódicos de
Nuevo León, 36.6\% ( $n=30)$, lo cual sugiere que los inmigrantes como actores protagonistas tienen el foco de atención sobretodo en los periódicos del estado del sur del país. Los periódicos digitales de Chiapas son los que más promueven actores protagonistas, $66.8 \%(n=125)$, y también son los que más promueven a los actores protagonistas antes mencionados.

\section{Tabla 1}

Actores protagonistas en los periódicos del norte y el sur

\begin{tabular}{lcccccc}
\hline $\begin{array}{l}\text { Periódicos/ } \\
\text { Actores protagonistas }\end{array}$ & \multicolumn{2}{c}{$\begin{array}{c}\text { Periódicos de Nuevo } \\
\text { León (Norte) }\end{array}$} & \multicolumn{2}{c}{$\begin{array}{c}\text { Periódicos de } \\
\text { Chiapas (Sur) }\end{array}$} & \multicolumn{2}{c}{ Total } \\
\hline \multirow{2}{*}{ Inmigrantes } & $n$ & $\%$ en actor & $n$ & $\%$ en actor & $n$ & $\%$ \\
Gobierno & 30 & $36.6 \%$ & 52 & $63.4 \%$ & 82 & $43.9 \%$ \\
Fuerzas del orden & 14 & $29.8 \%$ & 33 & $70.2 \%$ & 47 & $25.1 \%$ \\
Servicios de salud & 6 & $24.0 \%$ & 19 & $76.0 \%$ & 25 & $13.4 \%$ \\
Intelectuales & 1 & $25.0 \%$ & 3 & $75.0 \%$ & 4 & $2.1 \%$ \\
Colectivos sociales & 1 & $100.0 \%$ & 0 & $0.0 \%$ & 1 & $0.5 \%$ \\
Religión & 7 & $46.7 \%$ & 8 & $53.3 \%$ & 15 & $8.0 \%$ \\
Ciudadano común & 0 & $0.0 \%$ & 5 & $100.0 \%$ & 5 & $2.7 \%$ \\
Otros & 3 & $50.0 \%$ & 3 & $50.0 \%$ & 6 & $3.2 \%$ \\
Total & 0 & $0.0 \%$ & 2 & $100.0 \%$ & 2 & $1.1 \%$ \\
\hline Nota. Tonyyyyyyyyy & 62 & $33.15 \%$ & 125 & $66.8 \%$ & 187 & $100.0 \%$ \\
\hline
\end{tabular}

Nota. Total sobre las 120 notas analizada en la muestra. Cada nota puede obtener uno o más actores protagonistas. $n=$ 187 actores protagonistas.

\section{Actores implicados en la historia periodística}

Hay 290 menciones a actores implicados en las historias periodísticas (Tabla 2), de las cuales $68.6 \%(n=199)$ son positivas y $31.4 \%(n=91)$ son negativas. Los actores implicados en ambas formas, positivas y negativas, son los mismos que los actores protagonistas: los inmigrantes, los actores políticos y las fuerzas de seguridad.

\footnotetext{
${ }^{6}$ En sus distintos niveles.

${ }^{7}$ Fuerzas del orden: policía federal, estatal y municipal de México; fuerza aérea y ejército mexicano, la marina mexicana.
}

Global Media Journal México, 18(34), 137-159, enero - junio 2021. 
Tabla 2

Manera en la que se habla de cada actor implicado en el hecho

\begin{tabular}{|c|c|c|c|c|c|c|c|}
\hline & \multirow[t]{2}{*}{ Actores } & \multicolumn{2}{|c|}{$\begin{array}{c}\text { Periódicos de } \\
\text { Nuevo León (Norte) }\end{array}$} & \multicolumn{2}{|c|}{$\begin{array}{l}\text { Periódicos de } \\
\text { Chiapas (Sur) }\end{array}$} & \multicolumn{2}{|c|}{ Total } \\
\hline \multirow{11}{*}{$\begin{array}{l}\text { Forma } \\
\text { positiva }\end{array}$} & & $n$ & $\%$ en actor & $n$ & $\%$ en actor & $n$ & $\%$ \\
\hline & Inmigrantes & 27 & $44.3 \%$ & 34 & $55.8 \%$ & 61 & $30.7 \%$ \\
\hline & Actores políticos & 9 & $19.9 \%$ & 36 & $80 \%$ & 45 & $22.6 \%$ \\
\hline & Fuerzas de seguridad & 6 & $18.2 \%$ & 27 & $81.8 \%$ & 33 & $16.6 \%$ \\
\hline & Colectivos sociales & 8 & $42.1 \%$ & 11 & $57.9 \%$ & 19 & $9.6 \%$ \\
\hline & Sector Salud & 2 & $12.6 \%$ & 14 & $87.6 \%$ & 16 & $8.0 \%$ \\
\hline & Religión & 3 & $30.0 \%$ & 7 & $70 \%$ & 10 & $5.0 \%$ \\
\hline & Sociedad civil & 5 & $50.0 \%$ & 5 & $50 \%$ & 10 & $5.0 \%$ \\
\hline & Intelectuales & 2 & $66.6 \%$ & 1 & $33.30 \%$ & 3 & $1.5 \%$ \\
\hline & Otros & 1 & $50.0 \%$ & 1 & $50 \%$ & 2 & $1.0 \%$ \\
\hline & Total & 63 & & 136 & & $\begin{array}{c}199 \\
(68.6 \%)\end{array}$ & $100.0 \%$ \\
\hline \multirow{10}{*}{$\begin{array}{l}\text { Forma } \\
\text { negativa }\end{array}$} & Inmigrantes & 12 & $27.9 \%$ & 31 & $72.1 \%$ & 43 & $47.3 \%$ \\
\hline & Actores políticos & 14 & $60.8 \%$ & 9 & $39.1 \%$ & 23 & $25.3 \%$ \\
\hline & Fuerzas de seguridad & 6 & $50.0 \%$ & 6 & $50.0 \%$ & 12 & $13.2 \%$ \\
\hline & Sociedad civil & 4 & $66.7 \%$ & 2 & $33.3 \%$ & 6 & $6.6 \%$ \\
\hline & Colectivos sociales & 0 & $0.0 \%$ & 3 & $100.0 \%$ & 3 & $3.3 \%$ \\
\hline & Religión & 0 & $0.0 \%$ & 3 & $100.0 \%$ & 3 & $3.3 \%$ \\
\hline & Sector salud & 0 & $0.0 \%$ & 0 & $0.0 \%$ & 0 & $0.0 \%$ \\
\hline & Intelectuales & 0 & $0.0 \%$ & 0 & $0.0 \%$ & 0 & $0.0 \%$ \\
\hline & Otros & 0 & $0.0 \%$ & 1 & $100.0 \%$ & 1 & $1.1 \%$ \\
\hline & Total & 36 & & 55 & & $\begin{array}{c}91 \\
(31.4 \%)\end{array}$ & $100.0 \%$ \\
\hline Total & & & & & & 290 & $100.0 \%$ \\
\hline
\end{tabular}

Nota. Total sobre las 120 notas analizada en la muestra. Cada nota puede poseer uno o más actores implicados en el hecho. De manera positiva $n=199$. De manera negativa $n=91$.

Nuevamente los periódicos digitales de Chiapas son los que más contribuyen a las menciones positivas y negativas de los actores implicados. Sin embargo, los inmigrantes son más mencionados de forma negativa, $47.6 \%(n=43)$, que de forma positiva, 30.7\% $(n=61)$. Los periódicos digitales de Chiapas son los que más mención negativa hacen de los inmigrantes, $72.1 \%(n=31)$. En contraste, las fuerzas de seguridad tienen más menciones positivas,
$16.6 \%(n=33)$, que negativas, $13.2 \%(n=12)$, y los periódicos digitales de Chiapas son los que más contribuyen a esta manera de reportarlos. Como lo menciona una de las notas:

Además un total de 478 personas habian desistido de su solicitud de la condición de refugio y pidieron apoyo a las autoridades mexicanas para el retorno voluntario a su país; recibieron el apoyo 
de la Policía Federal y del Instituto Nacional de Migración para su traslado a su lugar de origen. (El Heraldo de Chiapas, 3 de noviembre 2018)

En esta noticia se observan los siguientes actores implicados en el hecho: las personas migrantes centroamericanos, la Policía Federal, el Gobierno Federal, el Alto Comisionado de las Naciones Unidas para los Refugiados (ACNUR), la Comisión Mexicana de Ayuda a Refugiados (COMAR), y el Instituto Nacional de Migración. Los migrantes, en dicha nota de El Heraldo de Chiapas, son mencionados de manera negativa.

Por otro lado, en la nota del diario $E l$ Orbe, las fuerzas del orden son mencionadas en un discurso que los presenta positivamente frente a los centroamericanos que tratan de cruzar la frontera.

Su imprudencia sólo provocó que los uniformados mexicanos activaran bombas de gas lacrimógeno, y que el equipo antimotines se les abalanzara. [...] Las autoridades migratorias de México a través de los mandos de la Policía Federal informaron que de manera ordenada habría atención médica, aseo personal y alimento para mujeres y niños principalmente, en los albergues habilitados (El Orbe, 20 de octubre 2018).

\section{Perspectiva del hecho en la historia periodística}

Dentro de la perspectiva desde la cuál es abordado el hecho en la historia periodística (Tabla 3), la más frecuente es la perspectiva política con un $36.0 \%(n=54)$, seguida de la perspectiva social con un $33.3 \%(n=50)$, y la perspectiva de seguridad con un $26.0 \%(n=39)$. Esto coincide de alguna forma con los actores protagonistas e implicados; no obstante, en ese caso los inmigrantes son los que mayor porcentaje en mención tienen. Lo anterior podría sugerir que a pesar de que se habla mucho de dichos actores, se politiza la perspectiva desde la cual se habla de ellos. En ambas perspectivas, la política y la social, los periódicos digitales de Chiapas son los que más aportan a ello, 66.7\% $(n=36)$ y $66.0 \%(n=33)$ respectivamente.

La siguiente idea obtenida de una de las noticias, por ejemplo, se ubica dentro de la perspectiva política. Aquí se observa una perspectiva centrada en la voz de los gobernadores de Coahuila y Chihuahua, quienes comentan acerca de la preparación estatal para recibir a la caravana. Además, también se menciona al presidente de la Coordinación Nacional de Oficinas Estatales de Atención a los Migrantes (CONOFAM):

Global Media Journal México, 18(34), 137-159, enero - junio 2021. 
Los Gobernadores de Coahuila, Miguel Ángel Riquelme, y de Chihuahua, Javier

Corral, garantizaron que sus entidades se encuentran preparadas para el eventual paso de la caravana migrante. Riquelme aseguró que se respetarán los derechos humanos de los centroamericanos y en todo momento se garantizará su seguridad, así como apoyo a los que necesiten comida, agua o refugio (El Norte, 11 de noviembre 2018).

\section{Tabla 3}

Perspectiva desde la cual es abordada el hecho en la nota

\begin{tabular}{lcccccc}
\hline \multirow{2}{*}{ Periódico/Perspectiva } & \multicolumn{2}{c}{ Periódicos de } & \multicolumn{2}{c}{ Periódicos } & \multicolumn{2}{c}{ Total } \\
& Nuevo León (Norte) & \multicolumn{2}{c}{ de Chiapas (Sur) } & \multicolumn{2}{c}{$\%$} \\
\cline { 2 - 7 } Política & $n$ & $\%$ & $n$ & $\%$ & $n$ & $\%$ \\
Social & 18 & $33.3 \%$ & 36 & $66.7 \%$ & 54 & $36.0 \%$ \\
Seguridad & 17 & $34.0 \%$ & 33 & $66.0 \%$ & 50 & $33.3 \%$ \\
Económica & 12 & $30.8 \%$ & 27 & $69.2 \%$ & 39 & $26.0 \%$ \\
Total & 3 & $42.9 \%$ & 4 & $57.1 \%$ & 7 & $4.7 \%$ \\
\hline
\end{tabular}

Nota. Total sobre las 120 notas analizada en la muestra. Cada nota puede poseer una o más perspectivas desde la cual es abordado el hecho. $n=150$ perspectivas.

\section{Encuadres en las historias periodísticas}

A pesar de que los 14 encuadres que a continuación se presentan se conforman de alrededor de tres a cinco indicadores, la Tabla 4 muestra la sumatoria de los indicadores en cada uno de dichos encuadres. Por ende, un total de 574 encuadres fueron identificados, tipificados y medidos según los encuadres pre-establecidos al inicio de la investigación. Entre estos, los más recurrentes son entrada irregular de inmigrantes, $17.2 \%(n=99)$, interés humano, $14.5 \%(n=83)$ y atribución de responsabilidad 10.5\% $(n=60)$. Los diarios digitales del estado de Chiapas, en todos los casos, son los que más contribuyen a dichos encuadres: $65.7 \%(n=65)$ al de entrada irregular de inmigrantes, $62.7 \%(n=52)$ al de interés humano, y $61.7 \%(n=37)$ al de atribución de responsabilidad.

Se identificó una ligera distinción entre los encuadres que dichos diarios le dan a las historias periodísticas, porque mientras que los de Chiapas encuadran la historia de la caravana migrante de 2018 en un tercer sitio con atribución de responsabilidad, 10.6\% $(n=37)$, los de Nuevo León lo hacen con conflicto, $12.0 \%$ $(n=27)$. 


\section{Tabla 4}

Comparación de encuadres por zona geográfica

\begin{tabular}{|c|c|c|c|c|}
\hline \multirow[t]{2}{*}{ Encuadres } & \multirow{2}{*}{$\begin{array}{c}\text { Periódicos } \\
\text { de Nuevo León } \\
\text { (Norte) }\end{array}$} & \multirow[t]{2}{*}{$\begin{array}{l}\text { Periódicos de } \\
\text { Chiapas (Sur) }\end{array}$} & \multicolumn{2}{|c|}{ Total } \\
\hline & & & $n$ & $\%$ \\
\hline 1. Entrada irregular de inmigrantes & 34 & 65 & 99 & $17.2 \%$ \\
\hline$\%$ dentro de zona geográfica & $34.3 \%$ & $65.7 \%$ & & \\
\hline$\%$ dentro de encuadre & $15.1 \%$ & $18.6 \%$ & & \\
\hline 2. Interés humano & 31 & 52 & 83 & $14.5 \%$ \\
\hline$\%$ dentro de zona geográfica & $37.3 \%$ & $62.7 \%$ & & \\
\hline$\%$ dentro de encuadre & $13.8 \%$ & $14.9 \%$ & & \\
\hline 3. Atribución de responsabilidad & 23 & 37 & 60 & $10.5 \%$ \\
\hline$\%$ dentro de zona geográfica & $38.3 \%$ & $61.7 \%$ & & \\
\hline$\%$ dentro de encuadre & $10.2 \%$ & $10.6 \%$ & & \\
\hline 4. Conflicto & 27 & 25 & 52 & $9.1 \%$ \\
\hline$\%$ dentro de zona geográfica & $51.9 \%$ & $48.1 \%$ & & \\
\hline$\%$ dentro de encuadre & $12.0 \%$ & $7.2 \%$ & & \\
\hline $\begin{array}{l}\text { 5. Descripción de la experiencia migratoria como } \\
\text { proyecto vital }\end{array}$ & 19 & 29 & 48 & $8.4 \%$ \\
\hline$\%$ dentro de zona geográfica & $39.6 \%$ & $60.4 \%$ & & \\
\hline$\%$ dentro de encuadre & $8.4 \%$ & $8.3 \%$ & & \\
\hline $\begin{array}{l}\text { 6. Debate político entorno a la política sobre } \\
\text { inmigración }\end{array}$ & 24 & 18 & 42 & $7.3 \%$ \\
\hline$\%$ dentro de zona geográfica & $57.1 \%$ & $42.9 \%$ & & \\
\hline$\%$ dentro de encuadre & $10.7 \%$ & $5.2 \%$ & & \\
\hline 7. Medidas de gestión de fronteras & 12 & 19 & 31 & $5.4 \%$ \\
\hline$\%$ dentro de zona geográfica & 38.70 & 61.29 & & \\
\hline$\%$ dentro de encuadre & $5.3 \%$ & $5.4 \%$ & & \\
\hline $\begin{array}{l}\text { 8. Tramitación de documentos y regularización de } \\
\text { inmigrantes }\end{array}$ & 14 & 12 & 26 & $4.5 \%$ \\
\hline$\%$ dentro de zona geográfica & $53.8 \%$ & $46.2 \%$ & & \\
\hline$\%$ dentro de encuadre & $6.2 \%$ & $3.4 \%$ & & \\
\hline $\begin{array}{l}\text { 9. Expulsión y devolución de los inmigrantes a su } \\
\text { país de origen }\end{array}$ & 4 & 20 & 24 & $4.2 \%$ \\
\hline$\%$ dentro de zona geográfica & 16.7 & $83.3 \%$ & & \\
\hline$\%$ dentro de encuadre & $1.8 \%$ & $5.7 \%$ & & \\
\hline 10. Consecuencias económicas & 10 & 14 & 24 & $4.2 \%$ \\
\hline$\%$ dentro de zona geográfica & $41.7 \%$ & $58.3 \%$ & & \\
\hline$\%$ dentro de encuadre & $4.4 \%$ & $4.0 \%$ & & \\
\hline $\begin{array}{l}\text { 11. Los inmigrantes como delincuentes y } \\
\text { vinculados con mafias u organizaciones delictivas }\end{array}$ & 3 & 20 & 23 & $4.0 \%$ \\
\hline$\%$ dentro de zona geográfica & $13.0 \%$ & $87.0 \%$ & & \\
\hline$\%$ dentro de encuadre & $1.3 \%$ & $5.7 \%$ & & \\
\hline
\end{tabular}


12. Los inmigrantes como víctimas de agresiones, malos tratos o actos xenófobos

$\%$ dentro de zona geográfica $\%$ dentro de encuadre

13. Contribución económica de los inmigrantes definidos como trabajadores

$\%$ dentro de zona geográfica

14. Moralidad

Total
$\%$ dentro de encuadre

$$
\% \text { dentro de zona geográfica }
$$$$
\% \text { dentro de encuadre }
$$

14

$60.9 \%$
$6.2 \%$

7

$31.8 \%$

$3.1 \%$

3

$17.6 \%$

$1.3 \%$

225

$39.2 \%$

$100.0 \%$
9

$23 \quad 4.0 \%$

$39.1 \%$

$2.6 \%$

15

$22 \quad 3.8 \%$

$68.2 \%$

$4.3 \%$

14

$17 \quad 3.0 \%$

$82.4 \%$

$4.0 \%$

349

$574 \quad 100.0 \%$

$\%$ dentro de zona geográfica

$\%$ dentro de encuadre

$60.8 \%$

$100.0 \%$

Nota. Total sobre las 120 notas analizadas en la muestra. Cada nota puede poseer uno o más encuadres. $n=574$ encuadres encontrados.

Los resultados de todas las tablas sugieren un vínculo

\section{Conclusiones}

entre los actores, protagonistas e implicados, la perspectiva desde donde se construye la historia periodística y los encuadres. Habría que identificar cuál es ese vínculo en futuros análisis. En la nota que lleva por título "Protestan tijuanenses contra migrantes", por ejemplo, se hace uso del encuadre de conflicto visiblemente; en el tabloide se narra la situación que viven los pobladores de Tijuana ante la llegada de una gran cantidad de migrantes. Dentro de la nota se menciona lo siguiente:

Alrededor de 100 vecinos de la colonia Playas de Tijuana se reunieron frente a la iglesia Estrella de Mar para manifestarse en contra de la llegada de migrantes centroamericanos, argumentando que podrían detonar un ambiente de inseguridad entre la comunidad (El Horizonte, 15 de noviembre 2018).

Como menciona Juárez Torres (2019), al principio de las precampañas de Estados Unidos en 2016 Trump no figuraba como el candidato con mayor potencial; logró su posicionamiento en el momento en que comenzó a atacar a las personas inmigrantes, a los mexicanos, y demás minorías en su discurso. Con la promesa de la construcción del muro fronterizo se colocó de inmediato en la agenda de los medios de comunicación, lo que no sólo le dio popularidad a él, sino también a los mismos inmigrantes, pero de forma adversa. La postura del presidente Andrés Manuel López Obrador, quien adaptó su estrategia debido a la presión política y mediática que ejerció Donald Trump hacia México, puso en marcha la política de confinamiento en la frontera sur de México con Guatemala, además del despliegue de la Guardia Nacional (Varela y McLean, 2019), lo que llevó a los individuos inmigrantes a verse obligados 
a cambiar su forma de migrar, formando así caravanas organizadas desde sus propios países de origen.

Como consecuencia de ello la sociedad develó su lado hospitalario, pero también quedó al descubierto el lado xenofóbico y racista de los mexicanos (Varela y McLean, 2019). Por un lado, es notable el esfuerzo realizado por organizaciones de la sociedad civil que recibieron a los inmigrantes; como lo menciona Tiscareño-García (2021), los mexicanos buscan ser solidarios con estos individuos inmigrantes. Sin embargo, la discriminación hacia estas personas también se pudo hacer notar en los encuadres de esta investigación, como lo sugieren los encuadres de entrada irregular de inmigrantes y conflicto.

Aunque durante la administración de López Obrador el gobierno reiteró mediante un comunicado el respeto a los derechos humanos de todas las personas migrantes (Secretaría de Gobernación de México, 2019), la situación para los migrantes sigue siendo complicada. Aunado a ello, la posición de López Obrador frente a esta situación fue cuestionada por diversos medios de comunicación tanto nacionales como internacionales, además de por los mismos mexicanos, sin dejar de lado la polémica causada por la actuación del Gobierno de México frente al arribo de personas migrantes provenientes del sur (Tiscareño-García, 2021).

$\mathrm{Si}$ bien es cierto que distintos autores discuten la perspectiva política (Canales Lizaola y Lizárraga Salas, 2019; De Cock et al., 2019; Guerra Salas y Gómez Sánchez, 2017; Lams, 2019; Tortajada, 2007) y los actores políticos (Carniel Bugs et al., 2018) desde distintos ángulos, en el presente estudio dicha perspectiva guarda una relevancia importante de frente a otras perspectivas como la social, la económica y la de seguridad. A diferencia de Canales Lizaola y Lizárraga Salas (2019) quienes identifican en los titulares de los tabloides de $L a$ Jornada, El Universal y La Opinión la temática social como la más recurrente seguida de la política, en el presente estudio se da a la inversa. Hay que enfatizar, sin embargo, que dicho estudio se enfocó en analizar la portada y primera plana, mientras que éste reviso el contenido de las historias periodísticas. Al igual que en los estudios de De Cock et al. (2019), y Guerra Salas y Gómez Sánchez (2017), en el presente estudio la perspectiva política obtiene el porcentaje más elevado, lo cual devela una forma uniforme de la prensa internacional al cubrir las noticias referentes a la migración. Es visible que los medios de comunicación aquí mencionados le otorgan mayor importancia al ángulo político en las notas periodísticas, dejando de lado el social, el de seguridad y el económico.

Lams (2019), Tortajada (2007) y Carniel Bugs et al. (2018) encuentran que las noticias en sus estudios relacionados con la migración destacan el rol de los actores políticos, y en menor medida en el caso del último estudio mencionado, las fuerzas del orden. En contraste, en el presente estudio los actores inmigrantes son los que tienen mayor prominencia como actores implicados en el hecho. Curiosamente al igual que en Carniel Bugs et al. (2018), tanto en la prensa del mediterráneo como en la de Nuevo León y Chiapas las fuerzas del orden ocupan un lugar importante. Los actores con mayor mención en las 
notas son los inmigrantes, por encima de los actores políticos. De manera similar, Ramos-Rojas y Martínez-Mendoza (2021) plantean a los migrantes como los principales actores en las notas de diez portales informativos mexicanos.

El producto de esta investigación esclarece también los encuadres más utilizados en las historias periodísticas de los diarios digitales de Chiapas y Nuevo León: los de interés humano y atribución de responsabilidad (Igartua y Muñiz, 2004; Muñiz, 2011), el de entrada irregular de inmigrantes (Igartua et al. 2004; Igartua et al. 2005; Muñiz et al. 2008; Ramos Rojas, 2015) y el encuadre de conflicto (Zuloaga, 2016). En ambos casos los encuadres de la entrada irregular de migrantes y el de interés humano son altamente utilizados. Los diarios de Chiapas utilizan también el de atribución de responsabilidad y, los de Nuevo León, el de encuadre de conflicto, lo que señala un interés particular de los diarios de Chiapas por señalar responsables del problema o señalar quién o quiénes tienen la capacidad para resolver el conflicto. Los diarios de Nuevo León no toman una postura concreta respecto al tema de la caravana de migrantes.

A pesar de que Igartua y Muñiz (2004) y Muñiz (2011) hacen sus estudios en función de la prensa de España y México, respectivamente, y en distinto momento, en el presente estudio los encuadres encontrados son muy similares, porque los de atribución de responsabilidad e interés humano se posicionan entre los más usados en los diarios de Nuevo León, mientras que los de interés humano y conflicto en Chiapas. Lo cual muestra un interés especial de los periodistas de distinto sitio y en distinto momento por encuadrar la noticia de la migración de la misma manera. En función del encuadre de conflicto, Tiscareño-García (2021) realiza un estudio de la caravana de migrantes 2018 utilizada para esta investigación, con la diferencia de que emplea tres diarios nacionales, en donde hace uso de la categoría de conflicto que ubica en segundo lugar, con la subcategoría de recepción y travesía, mientras que en la presente investigación el conflicto es ubicado en cuarto lugar. En ambas se muestra un interés de los medios por presentar al individuo migrante como un otro causante de disturbios.

Igartua et al. (2004), Igartua et al. (2005), Muñiz et al. (2008) y Ramos Rojas (2015) encuentran que el encuadre más predominante es el de entrada irregular de inmigrantes en pateras. En este trabajo se identifica en los diarios digitales de los dos estados el encuadre de entrada irregular de inmigrantes, pero a pie o en otro tipo de vehículos. Aunque en Zuloaga Lojo (2016) no se hace uso de los mismos encuadres, se encuentran similitudes en la manera de presentar en los titulares a los inmigrantes como protagonistas de sucesos delictivos, debido a que el encuadre de conflicto en el presente estudio se ubica entre los tres más usados en los periódicos del norte y con un porcentaje alto en los del sur, lo cual muestra que en ambos casos hay una inclinación por relacionar a las personas migrantes con sucesos conflictivos.

Se considera relevante que los diarios de Chiapas, estado situado en la frontera sur, se orienten en mayor medida al uso del encuadre de entrada irregular de inmigrantes. Cabe reflexionar el hecho de que los diarios de Nuevo León, estado 
geográficamente situado en el norte del país, utilicen el mismo encuadre. Las personas inmigrantes centroamericanos pertenecientes a la primera caravana son presentados como irregulares, y en menor medida como conflictivos por la prensa de los dos estados.

Estos hallazgos pueden resultar útiles para otros estudios respecto al consumo de las notas y la percepción del fenómeno. Al conocer la agenda de los medios y la manera en la que son encuadradas las notas referentes a la Caravana Migrante 2018 en Nuevo León y Chiapas, se obtiene una perspectiva de la situación desde el punto de vista de los medios de comunicación, y con ello es posible estar al tanto del tipo de información a la que la población de estos dos estados estuvo expuesta durante este período.

\section{Referencias bibliográficas}

Arango, J. (1985). Las “Leyes de las migraciones”; de E. G. Ravenstein, cien años después. Reis Revista Española de Investigaciones Sociológicas, (32), 7-26. https://doi.org/10.2307/40183172

Arango, J. (2003). La explicación teórica de las migraciones: Luz y sombra. Migración y Desarrollo, (1), 1-30. https://bit.ly/2RDN6wA

Ardèvol-Abreu, A. (2015). Framing o teoría del encuadre en comunicación. Orígenes, desarrollo y panorama actual en España. Revista Latina de Comunicación Social, (70), 423-450. https://doi.org/10.4185/RLCS2015-1053

Caballo, J. (20 de octubre de 2018). Codhem asistirá a Caravana Migrante a su paso por Edomex. Milenio, 1. https://bit.ly/3wbwgnK

Canales Lizaola, L. y Lizárraga Salas, F. (2019). El efecto Trump: la migración mexicana en la agenda mediática de la prensa de México y Estados Unidos: La Jornada, El Universal y La Opinión. INTERdisciplina, 7(18), 127-147. https://doi.org/10.22201/ceiich.24485705e.2019.18.68977

Carniel Bugs, R., Ortega Miranda, E. y Velázquez, T. (2018). El tratamiento de la información sobre flujos migratorios en los medios de los países mediterráneos. AdComunica, (16), 159-178. https://doi.org/10.6035/2174-0992.2018.16.9

Castillas, R. (2008). Las rutas de los centroamericanos por México, un ejercicio de caracterización, actores principales y complejidades. Migración y Desarrollo, 10, 157-174. https://doi.org/10.35533/myd.0610.rcr

Castillo, M. Á. y Toussaint, M. (2015). La frontera sur de México. Orígenes y desarrollo de la migración centroamericana. Cuadernos Intercambio sobre Centroamérica y El Caribe, 12(2), 59-87. https://doi.org/10.15517/c.a..v12i2.21700

Coleman, R., McCombs, M., Shaw, D. y Weaver, D. (2009). Agenda setting. En K. Wahl-Jorgensen y T. Hanitzsch (Eds.), The Handbook of Journalism Studies (pp. 147-160). Routledge.

Global Media Journal México, 18(34), 137-159, enero - junio 2021. 
De Cock, R., Sundin, E. y Mistiaen, V. (2019). The refugee situation as portrayed in news media: A content analysis of Belgian and Swedish newspapers 2015-2017. En L. D’Haenens, W. Joris, y F. Heinderyckx (Eds.), Images of immigrants and refugees in Western Europe (pp. 39-55). Leuven University Press.

De Vreese, C. (2005). News framing: Theory and typology. Information Design Journal + Document Design, 13(1), 51-62. https://doi.org/10.1075/idjdd.13.1.06vre

Observatorio de Legislación y Política Migratoria. (13 de diciembre de 2018). La caravana de migrantes centroamericanos en Tijuana 2018: Diagnóstico y propuestas de acción.El Colegio de la Frontera Norte. https://bit.ly/3gefili

El Heraldo de Chiapas. (7 de noviembre 2018). Más de tres mil migrantes centroamericanos han solicitado refugio en México. El Heraldo de Chiapas. https://bit.ly/3pQJCmQ

El Horizonte. (15 de noviembre de 2018). Protestan tijuanenses contra migrantes. El Horizonte. https://bit.ly/3whCClw

El Norte. (11 de noviembre de 2018). Garantizan atención Estados Fronterizos. El Norte. https://bit.ly/3vkMauI

El Orbe. (20 de octubre de 2018). Cercan y frenan caravana migrante en Suchiate. El Orbe. https://bit.ly/2TUppAM

Entman, R. M. (1993). Framing: Toward clarification of a fractured paradigm. Journal of Communication, 43(4), 51-58. https://doi.org/10.1111/j.1460-2466.1993.tb01304.x

Goffman, E. (1974). An essay on the organization of experience frame analysis. Northeastern University Press.

Guerra Salas, L. y Gómez Sánchez, M. E. (2017). La cobertura de las migraciones en la prensa de los países hispanohablantes (2016). Revista Nebrija de Lingüistica Aplicada a La Enseñanza de Lenguas, 11(23), 12-28. https://doi.org/10.26378/rnlael112328

Gutiérrez Rentería, M. E. (2018). Mexico. Digital News Report. https://bit.ly/3pAtMwK

Hérnandez, R., Fernández, C. y Baptista, P. (2014). Metodología de la investigación (6a ed.). McGraw-Hill.

Hertog, J. K. y McLeod, D. M. (2001). A multiperspectival approach to framing analysis: A field guide. En S. D. Reese, O. H. Grandy Jr., y A. E. Grant (Eds.), Framing Public Life. Perspectives on media and our understanding of the social world (pp. 141-162). Laurence Erlbaum Associates.

Igartua, J. J., Cheng, L., Moral, F., Fernández, I., Frutos, F. J., GómezIsla, J. y Otero, J. (2008). Encuadrar la inmigración en las noticias y sus efectos socio-cognitivos. Palabra Clave, 11(1), 87-107. https://bit.ly/3pDelnE

Igartua, J. J. y Humanes, M. L. (2004). El método científico aplicado a la investigación en comunicacion social. Portal de comunicación INCOM UAB, 2-18. https://bit.ly/2TmGiUy

Igartua, J. J., Humanes, M. L., Muñiz, C., Cheng, L., Mellado, C., Medina, E. y Erazo, M. Á. (24 de mayo de 2004). La información sobre inmigración e inmigrantes en la prensa española. ¿Barreras mediáticas a la

Global Media Journal México, 18(34), 137-159, enero - junio 2021. 
integración o imágenes que generan xenofobia? [Ponencia].Diálogo Comunicación y Diversidad Cultural Forum 2004, Barcelona, España. https://bit.ly/3gnS60u.

Igartua, J. J. y Muñiz, C. (2004). Encuadres noticiosos e inmigración: un análisis de contenido de la prensa y televisión españolas. Zer Revista de Estudios de Comunicación, 9(16), 87-104. https://bit.ly/3x2EcHO

Igartua, J. J., Muñiz, C. y Cheng, L. (2005). La inmigración en la prensa española. Aportaciones empíricas y metodológicas desde la teoría del encuadre noticioso. Migraciones, (17), 143-181. https://bit.ly/3wZmKnM

Igartua, J. J., Muñiz, C. y Otero, J. A. (2006). El tratamiento informativo de la inmigración en la prensa y la televisión española. Una aproximación empírica desde la teoría del Framing. Global Media Journal México, 3(5), 1-15. https://bit.ly/3g5i8Xr

Juárez Torres, D. (2019). Encuadre de la migración en la era de la posverdad: de los tuits de Trump a los portales de noticias mexicanos y estadounidenses. Temas y Problemas de Comunicación, 18, 38-45. https://bit.ly/3g16tcd

Krippendorff, K. (2004). Content Analysis. An Introduction to Its Methodology (2a ed.). Sage Publications.

Lams, L. (2019). Agency and power in the Dutch-Language news coverage of the summer 2015 refugee situation in Europe: A transivity analysis of semantic roles. En L. D’Haenens, W. Joris, y F. Heinderyckx (Eds.), Images of Immigrants and Refugees in Western Europe (pp. 83-99). Leuven University Press.

McCombs, M. (2006). Estableciendo la agenda. El impacto de los medios en la opinión pública y en el conocimiento. Paidós.

McCombs, M. (2014). Setting the agenda. The Mass Media and Public Opinion. Polity Press.

McCombs, M. y Ghanem, S. I. (2001). The Convergence of Agenda Setting and Framing. En S. D. Reese, O. H. Grandy Jr., y A. E. Grant (Eds.), Framing public life: perspectives on media and our understanding of the social world (p. 67-82). Lawrence Erlbaum Associates.

McCombs, M. y Valenzuela, S. (2007). The Agenda-Setting Theory. Cuadernos de Información, (20), 44-50. https://doi.org/10.7764/cdi.20.111

Muñiz, C. (2011). Encuadres noticiosos sobre migración en la prensa digital mexicana. Un análisis de contenido exploratorio desde la teoría del framing. Convergencia, 18(55), 213-239. https://bit.ly/3w91Gep

Muñiz, C., Igartua, J. J., De La Fuente, J. M. y Otero, J. A. (2007b). La inmigración latinoamericana en los contenidos informativos. Un estudio sobre las noticias de prensa y televisión españolas. Palabra Clave, 10(2), 75-91. https://bit.ly/3533yJW

Muñiz, C., Igartua, J. J. y Otero, J. A. (2007a). El Tratamiento de la Inmigración en los Medios de Comunicación. Un análisis comparativo entre prensa y televisión. En J. J. Igartua y C. Muñiz (Eds.), Medios de Comunicación, Inmigración y Sociedad (pp. 149-172). Universidad de Salamanca.

Global Media Journal México, 18(34), 137-159, enero - junio 2021. 
Muñiz, C., Igartua, J. J., Otero, J. A. y Sánchez, C. (2008). El tratamiento informativo de la inmigración en los medios españoles. Un estudio comparativo de la prensa y televisión. Perspectivas de la Comunicación, 1(1), 97-112. https://bit.ly/3ctbIiL

International Organization for Migration (IOM). (2019). Glossary on migration. IML Series 34. https://bit.ly/2TYao0Y

Ramos-Rojas, D. N. y Martínez-Mendoza, S. (2021). Alianza de Medios Tejiendo Redes. Estudios Sobre El Mensaje Periodístico, 27(1). https://doi.org/10.5209/esmp.71485

Ramos Rojas, D. (2015). Encuadres noticiosos en la cobertura mediática de la transmigración en México (20092011). Razón y Palabra, 19(2), 388-404. https://bit.ly/3cuBaUZ

Secretaría de Gobernación de México. (3 de agosto de 2019). INM comprometido con el respeto irrestricto a los derechos humanos. Gobierno de México. https://bit.ly/3w9aot7

Semetko, H. A. y Valkenburg, P. M. (2000). Framing European politics: A content analysis of press and television news. Journal of Communication, 50(2), 93-109. https://doi.org/10.1111/j.1460-2466.2000.tb02843.x

Solis Contreras, J. A. (2018). Fenómeno migratorio de tránsito por México y función de los albergues en la zona sur del país como centro de asistencia humanitaria. Memorias del XX Concurso Lasallista de $\begin{array}{lllll}\text { Investigación, } & \text { Desarrollo } & e & \text { Inovación, } & 5(1),\end{array}$ https://doi.org/https://doi.org/10.26457/mclidi.v5i1.1661

Tiscareño-García, E. (2021). Encuadres noticiosos sobre la Caravana Migrante del 2018 en periódicos digitales mexicanos. Estudios sobre el Mensaje Periodístico, 27(1). https://doi.org/10.5209/esmp.71436

Tortajada, I. (2007). Tratamiento informativo de los hechos en Ceuta y Melilla: análisis intersubjetivo e intercultural de contenido. En J. J. Igartua y C. Muñiz (Eds.), Medios de Comunicación, Inmigración y Sociedad (pp. 173-195). Universidad de Salamanca.

Valkenburg, P. M., Semetko, H. A. y De Vreese, C. H. (1999). The Effects of News Frames on Readers' Thoughts and Recall. Communication Research, 26(5), 550-569. https://doi.org/10.1177/009365099026005002

Van Dijk, T. A. (2006). Discurso de las élites y racismo institucional. En M. Lario Bastida, Medios de Comunicación e Inmigración (pp. 15-34). Convivir Sin Racismo.

Varela H., A., y McLean, L. (2019). Caravanas de migrantes en México: nueva forma de autodefensa y transmigración. Revista CIDOB d'Afers Internacionals, (122), 163-185. https://doi.org/10.24241/rcai.2019.122.2.163

Wimmer, R. y Dominick, J. (2001). Introducción a la investigación de medios masivos de comunicación. Thompson.

Zuloaga Lojo, L. (2016). La concepción securitaria de la inmigración en el caso español. Athenea Digital. Revista de Pensamiento e Investigación Social, 16(2), 215-244. https://doi.org/10.5565/rev/athenea.1548

Global Media Journal México, 18(34), 137-159, enero - junio 2021. 